\title{
The domestic iron. A danger to young children
}

\author{
Paul Gaffney
}

\begin{abstract}
Objectives-To study the epidemiology of thermal injury caused by the domestic iron in children 5 years old or less.

Methods-Retrospective review of case notes held in the accident and emergency (A\&E) department of a large teaching hospital over a 36 month period. Data regarding demographics, site and extent of injury, mechanism of injury and outcome were retrieved.

Results-62 thermal injuries were identified in 59 patients. Of these, 60 were contact burns and two were scalds. The male to female ratio was $2: 1$. The mean age was 24 months. Fifty five per cent were aged between 1 and 2 years old. The hand was the commonest site of injury (63\%) and, of these, two thirds were on the palm. Interestingly $10 \%$ occurred on the face. Iron contact burns accounted for $23.5 \%$ of all contact burns in this age group over this period. The majority of contact burns were partial thickness and most were less than $1 \%$ body surface area. Inadequate supervision is a recurring theme in many of these cases. A suspicion of nonaccidental injury was raised in 10 cases and confirmed in nine of these.

Conclusions-Iron burns are common in young children, particularly boys aged between 1 and 2 years old. Most can be treated in the $A \& E$ clinic. The potential for serious injury does exist. Nonaccidental injury always needs to be considered. Efforts at prevention and increasing public awareness are needed. (F Accid Emerg Med 2000;17:199-200)
\end{abstract}

St James's University Hospital, Beckett Street, Leeds LS9 7TF

Correspondence to: Dr Gaffney, Specialist Registrar in Accident and Emergency Medicine

Keywords: thermal injury; domestic iron; children

Inquisitive young children are, by their nature, unaware of the dangers of their environment. In this context the domestic iron has the potential to be a dangerous piece of household equipment. Up to $50 \%$ of burns in children occur in the first four years of life and the most

Accepted for publication 10 November 1999

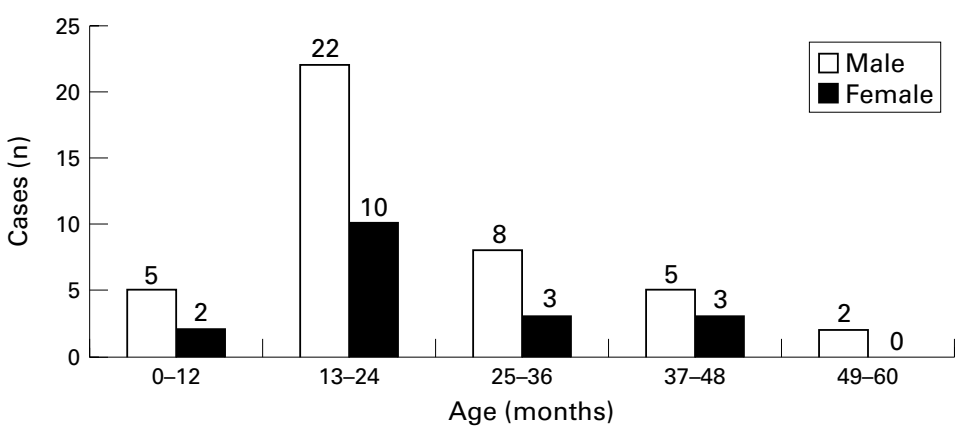

Figure 1 Contact burns as distributed by age and sex. common cause is scalding. Contact burns are the second commonest cause and occur when a heated object contacts skin and causes a well defined and usually small area of skin damage. A prospective study from Australia has identified in children of all ages that the domestic iron caused $19 \%$ of all contact burns (mean age 19 months and $80 \%$ involved the upper limb). ${ }^{1}$ A study from a specialist burns unit in the UK retrospectively identified the domestic iron as the commonest cause of contact burns in children under the age of 5 years. $^{2}$ This study recognised the potential for serious cosmetic and functional deformity. No published work has identified the extent of the problem among the paediatric accident and emergency (A\&E) population in the UK.

Against this background the principal aim of this work is to study the epidemiology of thermal injuries caused by the domestic iron in children aged 5 years or less.

\section{Methods}

Cases were identified retrospectively from health visitor records in the A\&E department of a large teaching hospital over a 36 month period. After identification the A\&E notes were reviewed. No tertiary referrals were included. Data were retrieved with regard to demographics of the injured children, site and extent of injury, mechanism of injury and outcome.

\section{Results}

From January 1996 to December 1998, 62 thermal injuries caused by the domestic iron were identified in 59 patients aged 5 years or less (three patients had two injuries simultaneously). Of these injuries 60 were contact burns and two were scalds (both were superficial and did not need follow up). The mean age was 24 months (range 5-57). Fifty five per cent of the children were aged between 1 and 2 years (fig 1). The male to female ratio was $2: 1$. Iron contact burns accounted for $23.5 \%$ of all contact burns in this age group over this period of time. Figure 2 shows the distribution of the contact burns.

Tables 1 and 2 show the depth and surface area of the contact burns. Typical features of contact iron burns are linear and triangular shaped injuries (fig 3 and fig 4).

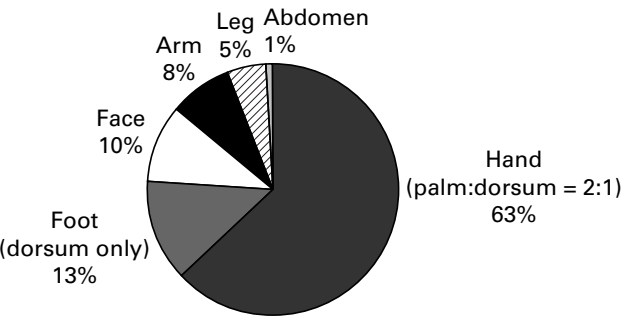

Figure 2 Distribution of contact burns by site. 


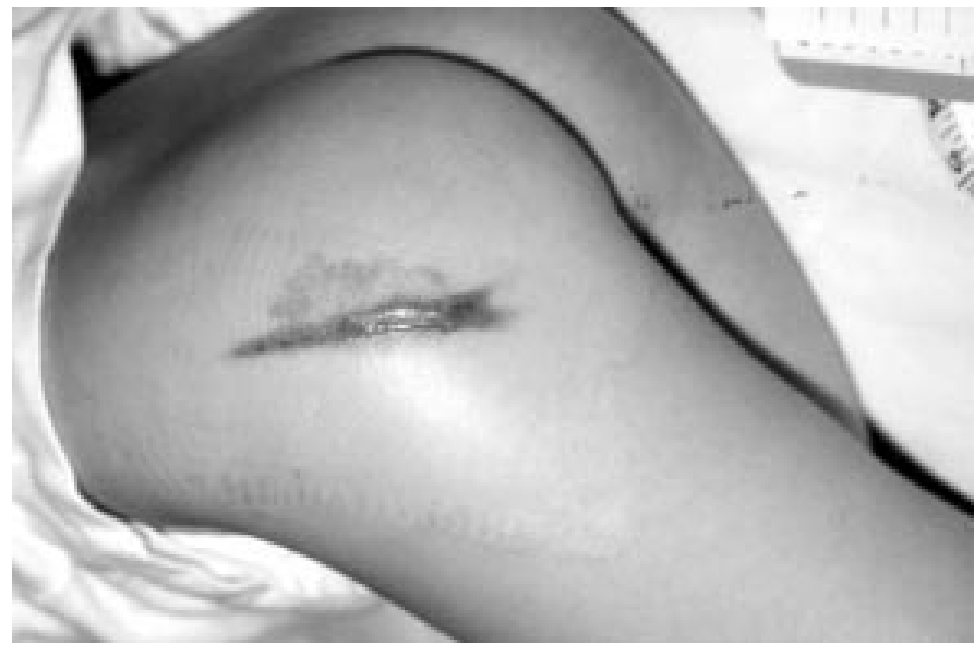

Figure 3 Linear iron burn.

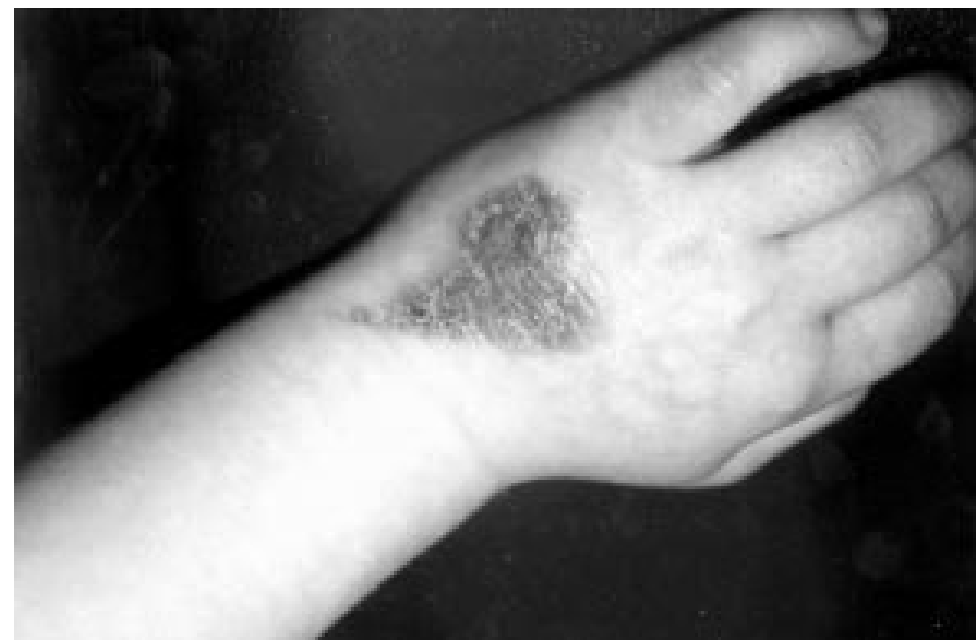

Figure 4 "Triangular"iron burn.

Table 1 Depth of contact burns

\begin{tabular}{ll}
\hline $\begin{array}{l}\text { Depth of contact } \\
\text { burn }\end{array}$ & $\begin{array}{l}\text { Cases } \\
(\%)\end{array}$ \\
\hline Partial thickness & 87 \\
Superficial & 10 \\
Full thickness & 3 \\
\hline
\end{tabular}

Table 2 Percentage body surface area of contact burns

\begin{tabular}{ll}
\hline$\%$ & Cases $(n)$ \\
\hline$<1$ & 53 \\
$1-5$ & 6 \\
$>5$ & 1 \\
\hline
\end{tabular}

The iron was turned off in nine of the cases (after recent use), 14 cases occurred when the iron was on a low table or on the floor and 12 cases occurred when the child tugged at the dangling flex.

The mean time to discharge for the 45 patients followed up in our A\&E clinic was 12 days (range 5-23). The only adverse sequel noted in this group of patients was secondary infection in seven cases. Three patients were referred to the plastic surgeon for consideration for grafting.

Ten patients were referred to community paediatrics because a suspicion of nonaccidental injury was raised. Of these, nine were considered to be non-accidental and were subsequently referred to social services. Features common to these cases include unusual site of injury (dorsum of hand and face), multiple burns, delay in presentation and inconsistent/incompatible history.

\section{Discussion}

The British Standards Institution issues guidelines on the soleplate temperature at various settings on the domestic iron (table 3 ). ${ }^{3}$ It has been shown that with pig and human skin water at a temperature of $70^{\circ} \mathrm{C}$ causes a full thickness
Table 3 Sole plate temperatures

\begin{tabular}{lll}
\hline \multirow{2}{*}{ Marking } & \multicolumn{2}{l}{ Sole plate temperature $\left({ }^{\circ} \mathrm{C}\right)$} \\
\cline { 2 - 3 } & Minimum & Maximum \\
\hline . (1 dot) & 70 & 120 \\
.. (2 dots) & 100 & 160 \\
. (3 dots) & 140 & 210 \\
Maximum & & 240 \\
\hline
\end{tabular}

injury after only one second of contact time. ${ }^{4}$ Taken together these facts emphasise the dangers associated with the domestic iron.

This study has highlighted certain important features of thermal injuries caused by the domestic iron in young children. The injury is particularly common in boys aged between 1 and 2 years old. This is the age at which children are just becoming mobile and the domestic iron is certain to arouse their interest. Injuries to the palm are the commonest. However, a significant number also occur on the dorsum of the hand and this is always a worrying feature of a contact burn in a young child. ${ }^{5}$ The potential for the domestic iron to cause large $(>1 \%)$ and deep (more than partial thickness) burns is recognised as is the potential to cause hot water and steam burns. Iron burns add considerably to the work of this urban $\mathrm{A} \& \mathrm{E}$ department. It is difficult to draw any firm conclusions regarding mechanism of injury from a retrospective case note review. Clearly the dangers of a cooling iron, the dangling flex and ironing on a low surface (particularly among Asian families) are not recognised. It would be interesting to compare our results with those of a department that serves a less deprived population. A prospective study collecting information about mechanism of injury, parental attitudes to ironing, cultural and social influences would also be helpful in further defining the epidemiology of thermal injuries caused by the domestic iron. This may help form the basis of a campaign to prevent this injury in the UK.

It is striking that nine of 59 cases were referred, after expert opinion, as cases of nonaccidental injury to social services. This high incidence of non-accidental injury has prompted ongoing research into this important area.

\section{Conclusion}

Iron burns are common in young children presenting to this department. The potential for serious injury does exist. Non-accidental injury always needs to be considered. Improved public awareness and measures to promote prevention are recommended to reduce the incidence of thermal injuries caused by the domestic iron.

I wish to thank Angela Scholes, Health Visitor and Medical Illustration, St James's University Hospital, Leeds.

Funding: none.

Conflicts of interest: none.

1 Hollyoak MA, Muller MJ, Pegg SP, et al. Electric iron contact burns in an Australian paediatric population. Paediatr Perinat Epidemiol 1994;8:314-24.

2 Datubo-Brown DD, Gowar JP. Contact burns in children. Burns 1989;15:285-6.

3 British Standards Institution. BSEN 60311:1998.

4 Moritz AR, Henriques FC. Studies on thermal injury. The relative importance of time and surface temperature in the causation of cutaneous burns. Am f Pathol 1947;23:695720 .

5 Hobbs CJ. When are burns accidental? Arch Dis Child 1986; 61:357-61. 